\title{
Gonadal and Sex Differentiation Abnormalities of Dogs and Cats
}

\author{
V.N. Meyers-Wallen \\ Baker Institute for Animal Health, College of Veterinary Medicine, Cornell University, Ithaca, N.Y., USA
}

\section{Key Words}

Cryptorchidism $\cdot$ Hermaphrodite $\cdot$ Hypospadias ·

Müllerian hypoplasia • Ovotesticular DSD · PMDS •

Sex chromosome DSD $\cdot$ Testicular DSD $\cdot$ XY DSD $\cdot$ XX DSD

\begin{abstract}
The molecular steps in normal sexual development were largely discovered by studying patients and animal models with disorders of sexual development (DSD). Although several types of DSD have been reported in the cat and dog, which are often strikingly similar to human DSD, these have been infrequently utilized to contribute to our knowledge of mammalian sexual development. Canine and feline cases of DSD with sufficient evidence to be considered as potential models are summarized in this report. The consensus DSD terminology, and reference to previous terminology, is used to foster adoption of a common nomenclature that will facilitate communication and collaboration between veterinarians, physicians, and researchers. To efficiently utilize these unique resources as molecular tools continue to improve, it will be helpful to deposit samples from valuable cases into repositories where they are available to contribute to our understanding of sexual development, and thus improve human and animal health.
\end{abstract}

Copyright $\odot 2011$ S. Karger AG, Basel
Other recent reviews have discussed the molecular mechanisms of normal mammalian sex determination or their application in understanding abnormal sexual development in domesticated animals [Villagomez et al., 2009; Poth et al., 2010; Jakob and Lovell-Badge, 2011]. To focus the diagnostic plan on factors that normally control each step in sexual development, we previously categorized affected dogs and cats according to the first step in sexual development that was abnormal, being either errors in chromosomal sex, gonadal sex, or phenotypic sex [Meyers-Wallen, 2009]. A new method of categorizing disorders of sexual development (DSD) has been developed for humans, to develop a consensus of diagnostic terms [Pasterski et al., 2010]. The consensus terminology is amenable to incorporation of molecular diagnosis, which is increasingly important, and adoption of a common nomenclature should facilitate communication and collaboration between veterinarians, physicians, and researchers. Accordingly, cats and dogs are now described as having DSD rather than being described as intersex. This review updates canine and feline cases that have sufficient diagnostic evidence to consider them as potential models for human DSD, but does not attempt to reinterpret all cases reported. The disorders are categorized as sex chromosome DSD, XY DSD, or XX DSD (table 1), but previous terminology is included in the text.

\section{KARGER}

Fax +4161306 1234 E-Mail karger@karger.ch www.karger.com
(C) 2011 S. Karger AG, Basel

www.karger.com/sxd
Vicki N. Meyers-Wallen

Baker Institute for Animal Health

College of Veterinary Medicine, Cornell University

Hungerford Hill Road, Ithaca, NY 14853 (USA)

Tel. +1 607256 5683, E-Mail vnm1@ cornell.edu 
Table 1. DSD in the cat and dog that are animal models or potential animal models for human DSD

\begin{tabular}{|c|c|c|c|}
\hline Species & Sex chromosome DSD & XY DSD & XX DSD \\
\hline Cat & $\begin{array}{l}\text { 39,XXY and variants } \\
37, \mathrm{X} \text { and variants } \\
\text { 39,XXX variants } \\
\text { 38,XX/38,XY chimerism }\end{array}$ & $\begin{array}{l}\text { Disorders of testicular development: } \\
\text { Ovotesticular DSD } \\
\text { Disorders in androgen synthesis or action: } \\
\text { Complete Androgen Insensitivity Syndrome (CAIS) } \\
\text { Other: } \\
\text { Persistent Müllerian Duct Syndrome } \\
\text { Isolated hypospadias } \\
\text { Isolated cryptorchidism }\end{array}$ & $\begin{array}{l}\text { Androgen excess, fetal: } \\
\text { 11-beta hydroxylase deficiency (CYP11B1) } \\
\text { Other: } \\
\text { Müllerian agenesis/hypoplasia } \\
\text { Vaginal atresia }\end{array}$ \\
\hline Dog & $\begin{array}{l}\text { 79,XXY } \\
77, \mathrm{X} \text { variants } \\
\text { 79,XXX and variants } \\
\text { 77,X/78,XY mixed gonadal dysgenesis } \\
\text { 78,XX/78,XY chimerism }\end{array}$ & $\begin{array}{l}\text { Disorders of testicular development: } \\
\text { Partial testicular dysgenesis } \\
\text { Ovotesticular DSD } \\
\text { Disorders in androgen synthesis or action: } \\
\text { Partial Androgen Insensitivity Syndrome (PAIS) } \\
\text { Other: } \\
\quad \text { Persistent Müllerian Duct Syndrome } \\
\text { Isolated hypospadias } \\
\text { Isolated cryptorchidism }\end{array}$ & $\begin{array}{l}\text { Disorders of ovarian development: } \\
\text { Ovotesticular DSD } \\
\text { Testicular DSD } \\
\text { Androgen excess, maternal: } \\
\text { Androgenic drugs } \\
\text { Other: } \\
\quad \text { Müllerian agenesis/hypoplasia }\end{array}$ \\
\hline
\end{tabular}

\section{Sex Chromosome DSD}

The normal chromosomal constitution of cats is $38, \mathrm{XX}$ or $38, \mathrm{XY}$, while that of dogs is $78, \mathrm{XX}$ or $78, \mathrm{XY}$. Several abnormalities in the number or structure of the sex chromosomes have been identified in cats and dogs. In general, however, sex chromosome DSDs are reported less frequently in these species than in human patients, as economic concerns influence the extent of diagnostic testing.

\section{$X X Y$ and Variants}

As in humans with Klinefelter syndrome, affected cats and dogs are phenotypic males that are sterile due to failure of spermatogenesis (fig. 1). There are many reports of $39, \mathrm{XXY}$ cats and mosaic variants such as XY/XXY and $\mathrm{XY} / \mathrm{XYY}$ [reviewed in Meyers-Wallen and Patterson, 1989]. The most comprehensive study discussed 25 cases [Centerwall and Benirschke, 1975] and another reported 14 cases [Leaman et al., 1999]. Most affected cats have been identified as unusual because they were phenotypic males having both black and orange in the hair coat (tortoiseshell or calico coat color). As the orange locus in the cat is X-linked [Grahn et al., 2005], and alleles at this locus are black or orange, a $38, \mathrm{XY}$ male should have either orange or black coat color.

In the dog, there is no coat color linked to the $\mathrm{X}$ chromosome, and only four 79,XXY dogs have been reported [Clough et al., 1970; Nie et al., 1998; Goldschmidt et al., 2001; Reimann-Berg et al., 2008]. One of these developed a scrotal testis tumor at 5 years of age [Goldschmidt et al., 2001]. However, it is not known whether 79,XXY dogs with scrotal testes have an increased risk of testicular neoplasia.

\section{Monosomy X and Variants}

As in human Turner's syndrome, cats and dogs with monosomy $\mathrm{X}$ develop as phenotypic females. Three cases of feline 37, X have been reported, 2 of which died by 3 days of age [Norby et al., 1974; Long and Berepubo, 1980]. Normal ovarian histology was reported in one of these [Norby et al., 1974]. Gonadal dysgenesis was identified in the third cat, which presented at 2.5 years of age with primary anestrus and small stature [Johnston et al., 1983]. Unilateral gonadal dysgenesis was identified in a fourth cat, a mosaic variant $(37, \mathrm{X} / 38, \mathrm{XX})$ that was pregnant at presentation [Thomsen et al., 1987].

There are few reports of canine $\mathrm{X}$ monosomy, all of which were phenotypic females, and some with small stature. However, all of these are likely mosaic variants. Two dogs presented with a history of persistent proestrus that failed to progress to estrus. The karyotype was reported as 77,X in the first case [Lofstedt et al., 1992] and $77, X / 78, X X$ in the second [Mayenco-Aguirre et al., 1999]. Gonadal histology was similar in both dogs, in that no follicles or corpora lutea were identified. As signs of proestrus were present in both dogs, they were likely 77,X/78, XX mosaics. Two other dogs presented for failure to become pregnant after exhibiting apparently normal estrous cycles and breeding at the appropriate time [Switonski et al., 
2003]. Both were determined to be $78, X X / 77, X$ mosaics in which the 77,X line was in low frequency. Another canine report of X monosomy [Smith et al., 1989] is discussed below (X/XY mixed gonadal dysgenesis).

\section{$X X X$ (and Variants)}

As in humans, XXX cats and dogs are phenotypic females having variable ovarian development and presentation. One feline mosaic variant $(37, \mathrm{X} / 39, \mathrm{XXX})$ had unilateral gonadal dysgenesis but was pregnant at presentation [Thomsen et al., 1987]. All 79,XXX dogs reported were phenotypic females, and most presented with primary anestrus [Johnston et al., 1985; Switonski et al., 2000; Goldschmidt et al., 2003]. However, 2 exhibited abnormal estrous cycles, including shortened interestrus intervals, persistent estrus, and anovulation [O'Connor et al., 2011]. Neither dog became pregnant when bred. Both ovaries in each dog were hypoplastic, in that normal follicles were absent. However, immature sex cords lined by granulosa cells were identified in 1 ovary of 1 of these dogs, confirming partial follicular development (fig. 2). Clinical signs of estrus in both dogs were most likely due to gonadal mosaicism $(78, \mathrm{XX} / 79, \mathrm{XXX})$.

\section{X/XY (Mixed Gonadal Dysgenesis)}

Only 1 dog has been reported in this category, which had a 77,X karyotype and was small in stature [Smith et al., 1989]. The external genitalia were ambiguous and the primary gonadal cell type resembled Leydig cells. Therefore, 77,X/78,XY gonadal mosaicism is likely [Giger et al., 1989].

\section{XX/XY (Chimerism, Ovotesticular DSD)}

Several feline 38,XX/38,XY chimeras have been reported, usually because they were phenotypic males with both orange and black in the hair coat [reviewed in Meyers-Wallen and Patterson, 1989; Leaman et al., 1999]. Some of these developed a testis and an ovary [Biggers and McFeeley, 1966; Malouf et al., 1967], others developed ovotestes. In some cases fertility or spermatogenesis was documented [Moran et al., 1984; Kuiper et al., 2003].

While several dogs with XX/XY karyotypes have been reported, gonadal histology was not performed in most [reviewed in Poth et al., 2010]. Many of these were evaluated because they had ambiguous genitalia, as shown in a $78, \mathrm{XX} / 78, \mathrm{XY}$ Fila Brasileiro (fig. 3; Meyers-Wallen [2001]). In comparison to littermates, the urogenital orifice was displaced caudally from the normal male posi-

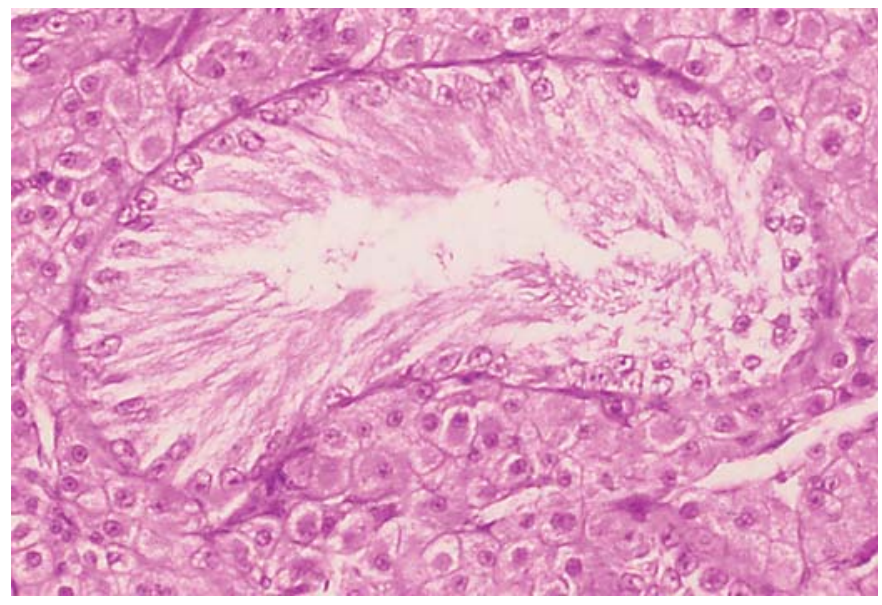

Fig. 1. Sex chromosome DSD. Testis histology from a 39,XXY cat. Only Sertoli cells are present in seminiferous tubules. Leydig cells are present in the interstitium.

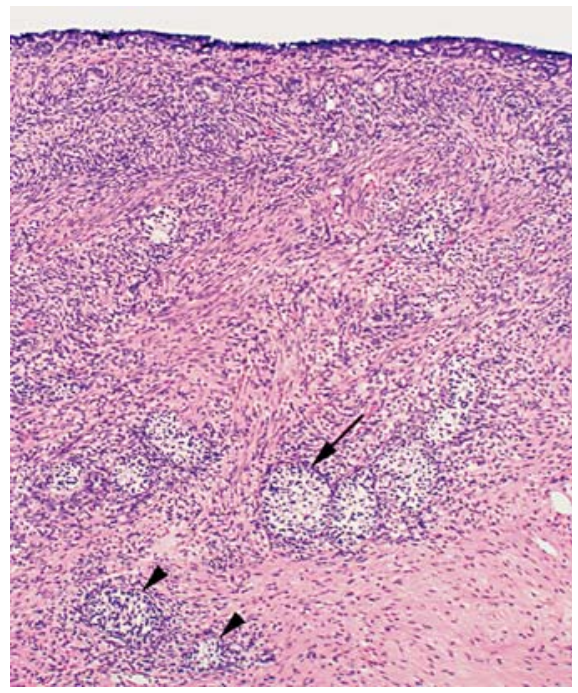

Fig. 2. Sex chromosome DSD. Histology of a hypoplastic ovary from a 79,XXX dog. There are subepithelial structures and cross sections of immature sex cords, varying from poorly differentiated follicles without oocytes (large arrow) to smaller ones resembling seminiferous tubules (arrowheads; reprinted from O'Connor et al. [2011], with permission from Elsevier).

tion and cranially from the female position. Both gonads in this dog contained seminiferous tubules and many Leydig cells. Although a small rim of cuboidal epithelium was present at the cortical surface in 1 area, no oocytes were present. Immature epididymides were present, but deferent ducts were absent. 


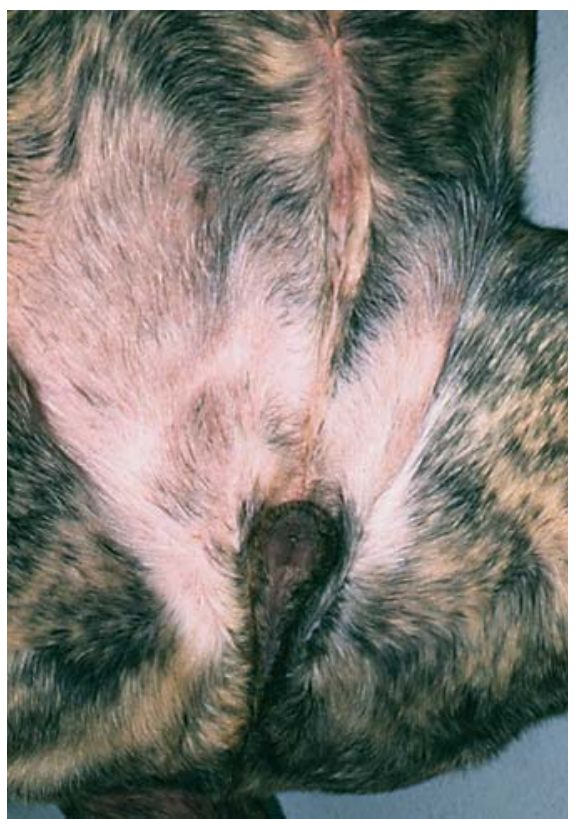

Fig. 3. Sex chromosome DSD. Ambiguous external genitalia of a $78, \mathrm{XX} / 78, \mathrm{XY}$ Fila Brasileiro dog. The prepuce is caudally displaced, being located closer to the anus and farther from the umbilicus (top of photograph) than in a normal male (reprinted with permission from International Veterinary Information Service, Ithaca, New York: Meyers-Wallen [2001]).

\section{XY DSD}

\section{Disorders of Testicular Development}

Complete or Partial Testicular Dysgenesis

This has not been reported in cats, but a few dogs with 78 ,XY karyotype and incompletely masculinized genitalia have been reported. Three cases have sufficient information to propose a diagnosis in this category. An $S R Y$ positive poodle presented with ambiguous external genitalia, consisting of an enlarged clitoris protruding from the vulva [Meyers-Wallen et al., 1999]. The gonads, both undescended testes, were confirmed by histology to contain seminiferous tubules lined by Sertoli cells lacking germ cells. The testes were attached to the horns of a bicornuate uterus in which the endometrial glands were small in size and number. Since both androgen- and Müllerian inhibiting substance (MIS)-dependent masculinization were incomplete in this case, it is likely to be a disorder of testicular development, but the molecular etiology is unknown.

A second case reported was a 78,XY mixed breed dog with female external genitalia and no evidence of clitoral enlargement [Bigliardi et al., 2011]. The dog presented at
8 years of age with subcutaneous swellings lateral to the vulva, which contained gonads with Leydig cell and Sertoli cell tumors. Deferent ducts and Müllerian duct derivatives were apparently absent. The presence of bilateral testicular neoplasia precludes definitive judgment on the extent of testicular dysgenesis. SRY was present, and contained a single nucleotide polymorphism, the significance of which is unknown. Therefore this case is likely a disorder of testicular development or of androgen synthesis or action (see disorders of androgen synthesis or action below). The molecular etiology is unknown.

A final case was a 78,XY Labrador retriever that was $S R Y$-positive and presented with an enlarged clitoris protruding from the vulva [Wernham and Jerram, 2006]. One testis was located in the subcutaneous skin near the vulva, and the other was in the abdomen. Histologic evaluation confirmed hypoplasia, as both testes contained seminiferous tubules without spermatogenesis and many Leydig cells in the interstitium. In addition, incompletely developed epididymides were adjacent to each testis, and deferent ducts were not found. No Müllerian duct derivatives were identified. Since only partial androgen-dependent masculinization, but complete MIS-dependent masculinization was confirmed in this case, it is likely a disorder of testicular development or of androgen synthesis or action. The molecular etiology is unknown.

\section{Ovotesticular DSD}

One case of feline ovotesticular DSD (XY sex reversal, true hermaphrodite) has been confirmed [Schlafer et al., 2011]. The 1-year-old mixed breed, phenotypically male cat presented with bilateral cryptorchidism (fig. 4). The karyotype was $38, \mathrm{XY}$ and the SRY nucleotide sequence was the same as in a normal male control. Ovotestes, located at the caudal pole of the kidneys, were composed primarily of testis, with a thin cortical rim of ovarian tissue. A complete bicornuate uterus, oviducts, and fimbria were present. Epididymides were adjacent to each gonad, but deferent ducts were adjacent only to the cranial portion of the uterine horns. The causative mutation is unknown.

Two likely cases of canine ovotesticular DSD have been reported. The first was a 78,XY mixed breed [reviewed in Chaffaux and Cribiu, 1991] and the second a 78,XY Yorkshire terrier [Jurka et al., 2009]. The first had ambiguous genitalia, including an enlarged clitoris with a bone. One gonad was an ovary containing atretic follicles without oocytes. The other was a testis containing a Sertoli cell tumor and seminiferous tubules lacking germ 
Fig. 4. XY DSD, ovotesticular. a External genitalia of a cat affected with ovotesticular DSD. The cat is in standing position, such that the nonpigmented anus is dorsal, the penis is ventral, and the scrotum, which does not contain testes, is between the anus and penis. Hair surrounding the scrotum and prepuce is pigmented. $\mathbf{b} \mathrm{Bi}-$ lateral ovotestes were present. A band of connective tissue separated the smaller cortical rim of ovarian tissue from the larger medullary testis. Rare primordial follicles and oocytes were observed. The central medullary region contained Leydig cells, small irregular sex cords and hypoplastic seminiferous tubules lined by Sertoli cells (reprinted with permission from Veterinary Pathology: Schlafer et al. [2011]).
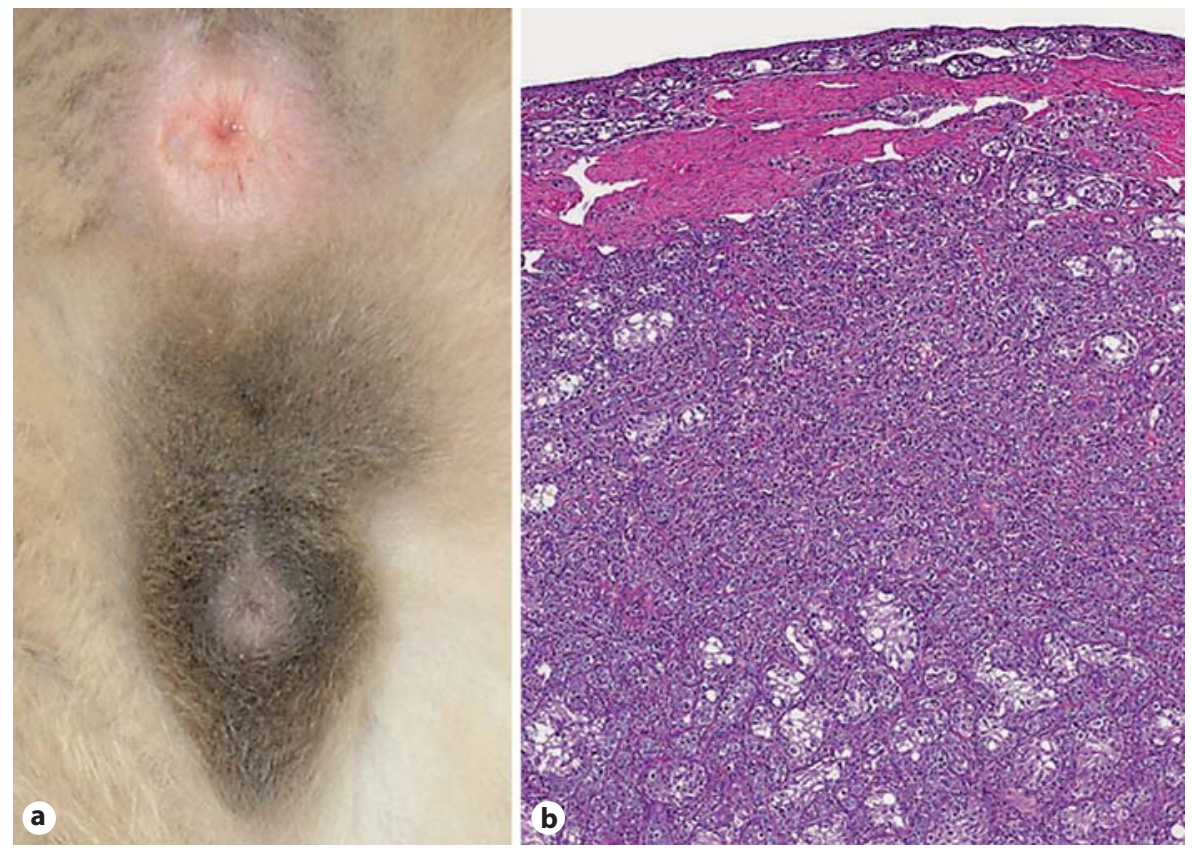

cells. In the second case, histologic confirmation of the gonads and a test for SRY were not performed.

\section{Disorders in Androgen Synthesis or Action}

Complete Androgen Insensitivity Syndrome

One case of feline complete androgen insensitivity syndrome has been reported in a 38,XY cat [Meyers-Wallen et al., 1989a]. The external genitalia were unambiguously female at 6 months of age when presented for routine ovariohysterectomy. The gonads were found at the caudal pole of the kidneys, and both Müllerian and Wolffian duct derivatives were absent. The vagina was blind-ended. The testes contained seminiferous tubules widely separated by interstitium containing abundant Leydig cells (fig. 5). Inability of the androgen receptor to bind tritiated dihydrotestosterone in fibroblasts cultured from the vulva was demonstrated in vitro.

\section{Partial Androgen Insensitivity Syndrome}

One case of canine partial androgen insensitivity syndrome was reported in a 78, XY mixed breed dog [Peter et al., 1993]. It was phenotypically female at 6 months of age, but scrotal-like swellings containing testes were later identified on each side of the vulva. A blind vaginal pouch was present. Gonadotropin-stimulated serum testosterone and dihydrotestosterone concentrations, and gonadal 5 alpha reductase enzyme activity were not significantly different from controls. Spermatogenesis was absent in

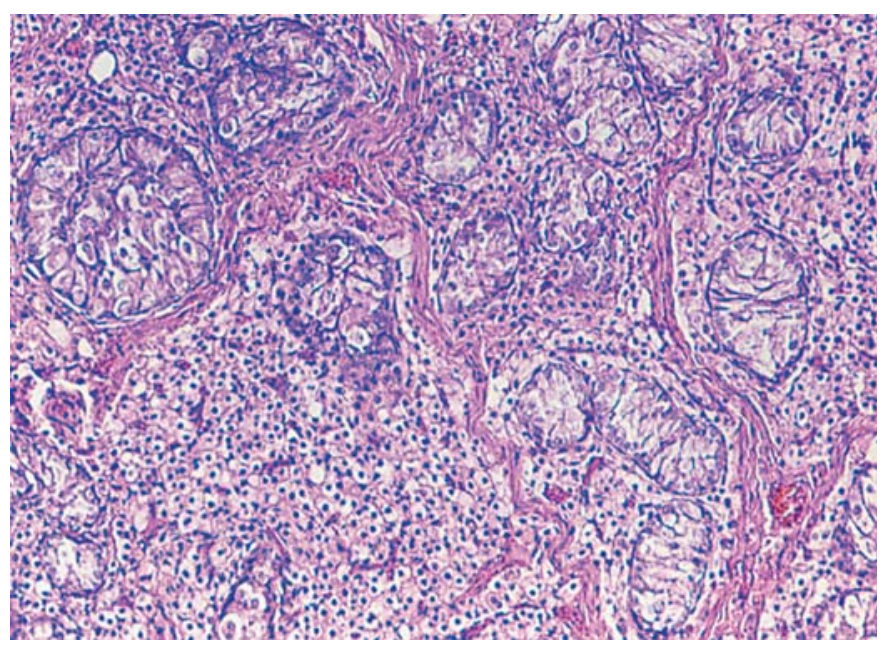

Fig. 5. XY DSD, disorder of androgen action. Testis histology from a 6-month-old cat lacking functional androgen receptors (complete androgen insensitivity syndrome, Meyers-Wallen et al. [1989a]). The overall architecture is disorganized. Germ cells and Sertoli cells are present within irregular seminiferous tubules lacking spermatogenesis. Leydig cells are present in the interstitium.

both hypoplastic testes. A well-developed epididymis and partially developed deferent duct were adjacent to each testis. High affinity binding of tritiated dihydrotestosterone in vitro was undetectable in fibroblasts cultured from the vulva. 
Fig. 6. XY DSD, PMDS. Gross features of the reproductive tract in an affected miniature schnauzer. a Complete reproductive tract. b, c Portions of a longitudinally bisected formalin-fixed reproductive tract. b The cranial vagina enters the dorsal prostate gland. c Müllerian duct derivatives cranial to the prostate gland include the cervix and the uterine body. $\mathbf{d}$ Cross section of uterine horn and adjacent deferent duct, coursing in parallel. e Seminiferous tubule in a scrotal testis from a 6-yearold PMDS dog, showing normal stages of spermatogenesis. $\mathrm{T}=$ Testis; $\mathrm{UH}=$ uterine horn; $\mathrm{P}=$ prostate gland; $\mathrm{B}=$ urinary bladder; $\mathrm{PE}=$ penis; $\mathrm{V}=$ cranial vagina; $\mathrm{UR}=$ urethra; $\mathrm{UB}=$ uterine body; $\mathrm{C}=$ cervix (reprinted with permission from Journal of Andrology: Wu et al. [2009]).
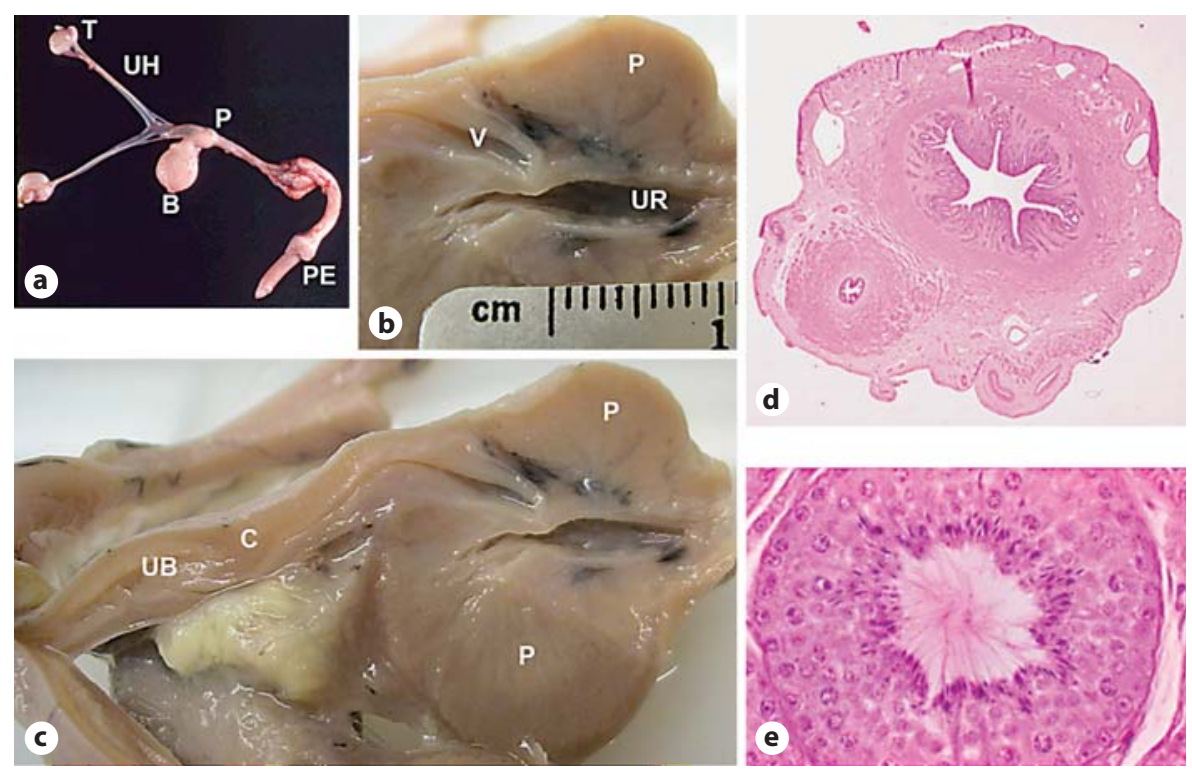

\section{Other}

Persistent Müllerian Duct Syndrome

This category is etiologically divided into disorders in the synthesis or action of MIS, also known as anti-Müllerian hormone (AMH). Mutations in MIS or its type II receptor (MISRII/AMHR2) cause the same phenotype. Only a few cases have been reported of phenotypically male cats having internal Müllerian duct derivatives, and these lack critical diagnostic tests. Nevertheless, it is likely that some of these are feline persistent Müllerian duct syndromes (PMDS). For example, a complete uterus was identified in a bilaterally cryptorchid, phenotypically male cat [Schulman and Levine, 1989]. Clinical signs of stranguria and infection prompted surgical intervention during which a bicornuate uterus filled with purulent exudate was identified. With the advent of the feline genome, molecular diagnosis can be pursued in such cases.

Canine PMDS has been reported frequently in the miniature schnauzer breed, in which the causative mutation appears to be widely distributed [Brown et al., 1976; Marshall et al., 1982; Matsuu et al., 2009; Vegter et al., 2010; Breshears and Peters, 2011]. Early studies establishing a research model from this breed determined that it was inherited as a sex-limited, simple autosomal recessive trait [Meyers-Wallen et al., 1989b]. As fetal and neonatal testes of PMDS dogs produced biologically active MIS, a defect in the MIS receptor or its downstream signaling pathway was suspected as the cause [Meyers-Wallen et al., 1989b, 1993]. Subsequently, a single base pair substitution in MISRII was identified, which introduces a stop codon in exon 3 [Wu et al., 2009]. The homozygous mutation should terminate translation at 80 amino acids, eliminating much of the extracellular domain and the entire transmembrane and intracellular signaling domains of the receptor. A mutation test for the miniature schnauzer is available [Pujar and Meyers-Wallen, 2009]. Canine PMDS has also been reported in the basset hound in Europe and a mixed breed dog, in which the causative mutations are unknown [Nickel et al., 1992; Kuiper et al., 2004].

The phenotype in the miniature schnauzer model is strikingly similar to that of human PMDS patients. Externally, affected dogs are unambiguously male, except that approximately $50 \%$ are unilaterally or bilaterally cryptorchid. Internally, all Müllerian and Wolffian duct derivatives are present. Bilateral oviducts and epididymides are adjacent to the testes. The deferent ducts are included in the lateral walls of the uterus, and the cranial ends of each uterine horn are attached to the caudal pole of the ipsilateral testis (fig. 6). The cervix is present, and the cranial vagina terminates within the craniodorsal aspect of the prostate gland. Radiographic contrast studies of 3 affected dogs confirmed a patent connection between the cranial vagina and the prostatic urethra (fig. 7). Uterine infection (pyometra) and neoplasia in cryptorchid testes are well documented sequelae to PMDS in the miniature schnauzer [reviewed in $\mathrm{Wu}$ et al., 2009].

The canine model provides clinical insight for PMDS patients [Wu et al., 2009]. Most are diagnosed as children at the time of surgical correction for cryptorchidism, and others are identified as infertile adults. Notably, cryptor- 


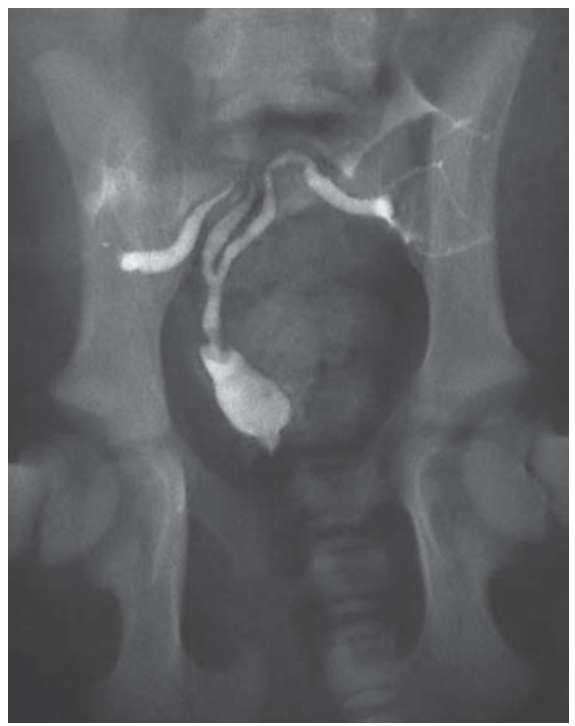

Fig. 7. XY DSD, PMDS. Ventrodorsal radiograph of a 6-week-old PMDS dog. Contrast dye was injected retrograde via a balloon catheter into the prostatic urethra. Contrast fills the dilated prostatic urethra, the cranial vagina, the uterine body and both uterine horns, confirming a patent connection between the cranial vagina and the prostatic urethra. The prostate parenchyma, which does not contain contrast, surrounds the cranial vagina (radiograph courtesy of Don Schlafer).

chidism and infertility are not consistently associated with canine PMDS. Fifty percent of affected dogs in the model pedigree had scrotal testes and appeared externally to be normal males. The remaining $50 \%$ were cryptorchid. We speculate that the close attachment of the testis to the uterine horn physically interferes with testis descent. PMDS dogs with at least 1 scrotal testis were fertile [Wu et al., 2009]. Therefore, more studies may be warranted to determine the proportion of PMDS patients who are neither cryptorchid nor infertile, and the frequency of secondary infections.

\section{Isolated Hypospadias}

Isolated hypospadias has been rarely reported in cats and dogs, and no molecular etiology has yet been identified in either species. Two reports in Himalayan cats described the severe phenotype [Bredal et al., 1997; King and Johnson, 2000]. The scrotum is bifurcated by a urethral canal that is open along the entire dorsal aspect, and the penis and prepuce are diverted dorsally. This phenotype has also been identified in a 38,XY domestic short hair cat in which normal stages of spermatogenesis were confirmed in testis histology (fig. 8).
Canine isolated hypospadias of varying severity has been reported (fig. 9). The location of the urethral orifice ranges from the glans penis (mild), to the penile shaft (moderate, Ndikuwera [2005]) to the perineum (severe, Ader and Hobson [1978]; Adelsberger and Smeak [2009]). The Boston terrier breed had the highest prevalence of isolated hypospadias in a survey of hospital cases in which affected purebred and mixed breed dogs were identified [Hayes and Wilson, 1986]. As it is likely familial in the Boston terrier, studies in this breed could serve as a model for humans. Hypospadias has also been reported in association with other canine abnormalities, such as cryptorchidism [Hayes and Wilson, 1986; Cassata et al., 2008], scrotal abnormalities [Jurka et al., 2009], anorectal defects [Hayes and Wilson, 1986; Cashmore and Ladlow, 2010], and XX DSD (below).

\section{Cryptorchidism}

Cryptorchidism can be associated with other DSD in cats or dogs, but particularly in dogs, it is usually reported as an isolated defect. The discussion below is limited to isolated cryptorchidism, in which XY males are phenotypically male, with the only exception being that 1 or both testes are undescended. The undescended testis may be located anywhere along the testis descent pathway, from the caudal pole of the kidney to the inguinal canal, or external to the canal but cranial to the scrotum [reviewed in Meyers-Wallen, 2009]. Thus, cryptorchidism is a term encompassing several phenotypic categories, likely reflecting a genetically complex control of testis descent.

As scrotal testes are not easily palpable in young kittens, the diagnosis of cryptorchidism is usually made in young males presented for neutering before 1 year of age. Feline cryptorchidism has been infrequently reported, and appears to be uncommon. In 1 hospital survey of 1,345 male cats admitted for neutering in a 10 -year period, only $1.7 \%$ were cryptorchid [Millis et al., 1992]. In another study over 4.5 years, $1.3 \%$ of male cats presented were cryptorchid [Yates et al., 2003]. In both studies, most affected cats were unilateral cryptorchid. The prevalence in Persian cats was significantly greater than in other breeds [Millis et al., 1992]. The molecular etiology of feline cryptorchidism is unknown.

Canine testes are undescended at birth. At the end of gestation, the testis lies on the peritoneal side of the internal inguinal ring, but passes through the inguinal canal within 10 days after birth [Gier and Marion, 1969]. However, it is unclear when the canine testis becomes secured to the scrotum [reviewed in Meyers-Wallen, 2009]. Clini- 

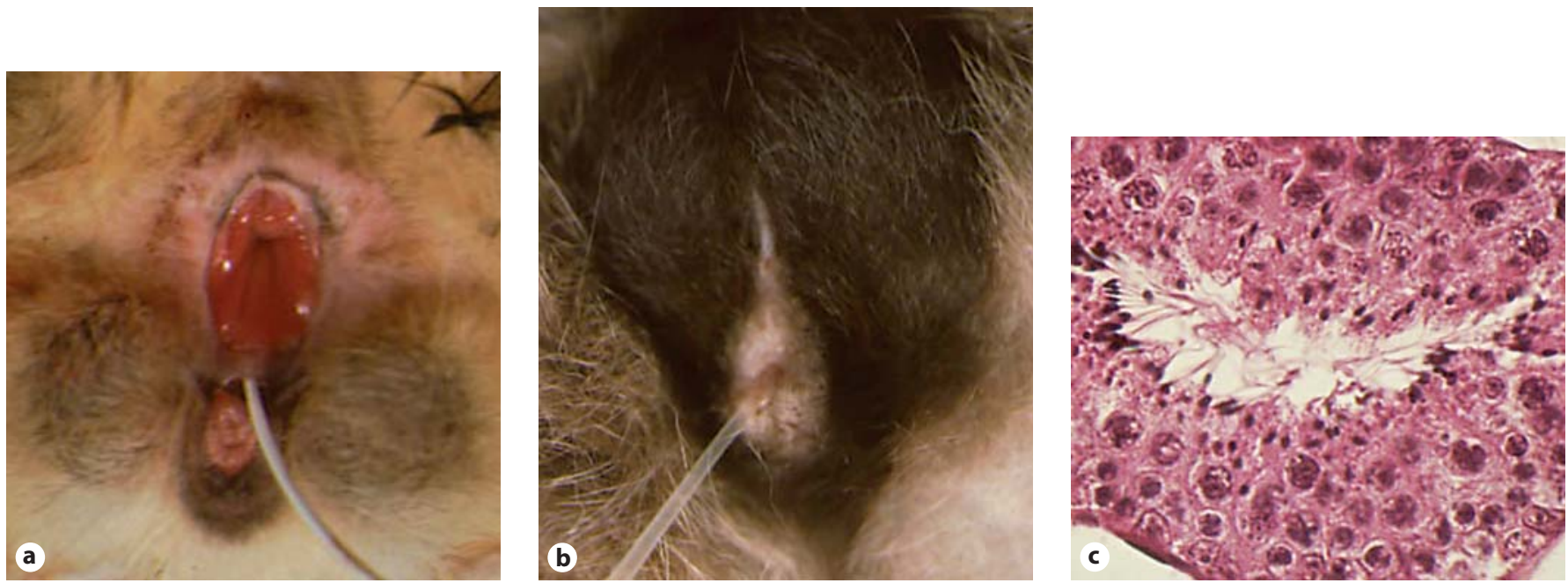

Fig. 8. XY DSD, perineal hypospadias. External genitalia of a an affected and $\mathbf{b}$ a normal male cat, each in standing position with a catheter placed in the urethra. a The scrotum is bisected due to failure of closure of the prepuce and penile urethra, causing severe hypospadias. The urethra is open along the entire dorsal aspect, and the urethral orifice is directly ventral to the anus (photo cour- tesy of Peter Jezyk). b The normal cat scrotum is fused along the midline and lies dorsal to the penis and ventral to the anus. Hair surrounding the scrotum and prepuce is darkly pigmented in this cat. c Affected cat, representative testis histology in which all stages of spermatogenesis were identified.

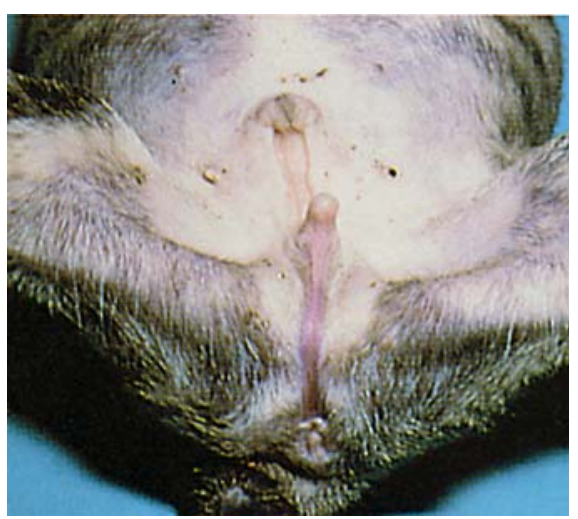

Fig. 9. XY DSD, perineal hypospadias. The external genitalia of a mixed breed terrier dog, shown from the ventral aspect. The urethra and prepuce are open along the entire ventral aspect. The scrotum is bisected and the urinary orifice is located directly ventral to the anus. The penile shaft is diverted caudally (reprinted with permission from Journal of the American Animal Hospital Association: Ader and Hobson [1978]).

cal diagnosis of canine cryptorchidism is warranted if the testes are undescended by $6-8$ weeks of age, when pups are routinely examined for first vaccinations. In contrast to the cat, canine cryptorchidism is prevalent, ranging from $6.8 \%$ of males presented for neutering [Yates et al., 2003] to $1.4 \%$ of dogs at 6-12 months of age [Hayes et al., 1985]. It is also more prevalent in some breeds [Reif et al., 1979; Hayes et al., 1985; Yates et al., 2003]. In 1 study, inguinal cryptorchid testes were most common [Yates et al., 2003].

As in humans, late testis descent has been identified in dogs. In 1 study of cryptorchid dogs examined regularly until 1 year of age, late descent occurred in $24.6 \%$ of cryptorchid testes, with $63.3 \%$ of those being unilaterally cryptorchid [reviewed in Meyers-Wallen, 2009]. However, most that descended did so by 14 weeks of age and none descended after 6 months of age. In humans, late testis descent has been associated with heterozygous null insulin-like 3 (INSL3) mutations [Tomboc et al., 2000], but this has not been reported in dogs. An increased risk of neoplasia in undescended testes is well documented, estimated as 12.7/1,000 dog-years at risk [Reif et al., 1979; Hayes et al., 1985]. To prevent neoplasia and reduce the frequency of cryptorchidism in purebred dogs, affected dogs are usually neutered.

The molecular basis for the various types of canine cryptorchidism is unknown, but is likely to be polygenic and genetically heterogeneous between breeds. The genetic etiology of canine cryptorchidism is now being pursued with genome wide association studies [Zhao et al., 2010] and candidate gene studies [Arrighi et al., 2010]. In breeds where cryptorchidism has been associated with other DSD, such as PMDS in the miniature schnauzer 


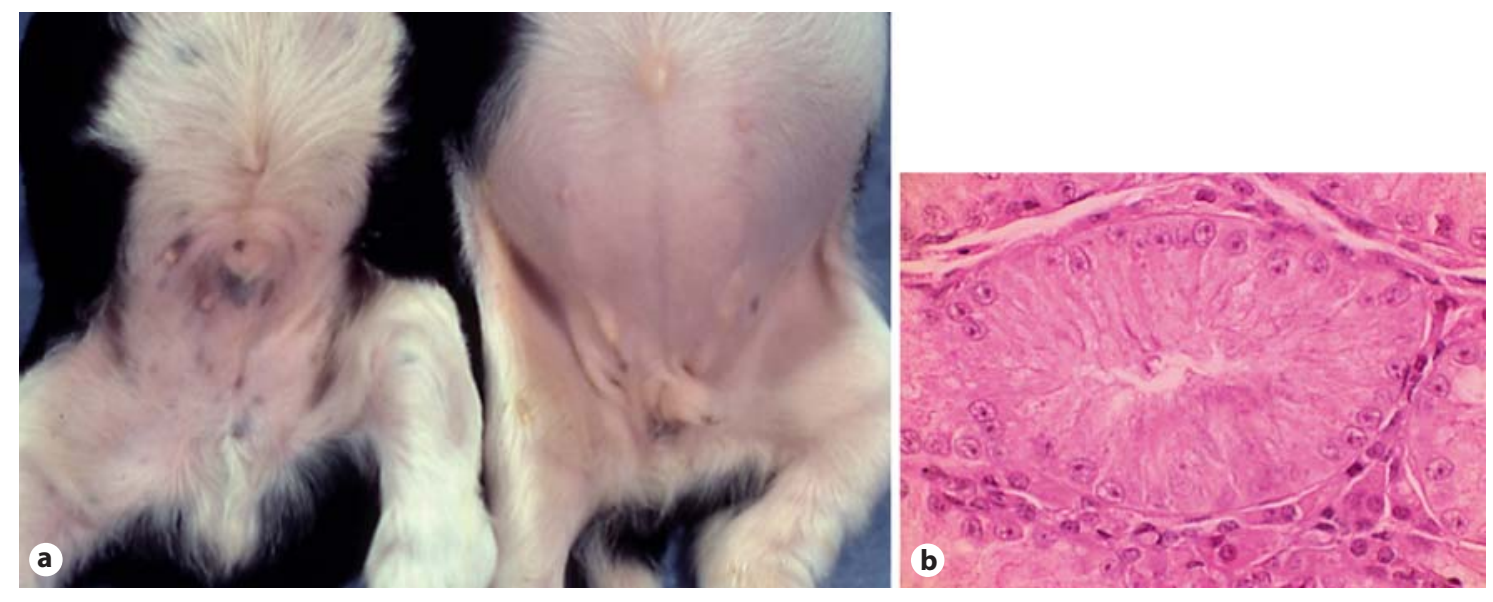

Fig. 10. XX DSD, testicular. a Normal XY male littermate (left) to an XX male (right) from the canine ACS research model pedigree. The affected pup is bilaterally cryptorchid and the penis and prepuce are caudally displaced. Mild hypospadias is also present (not shown). b Histology of the testis from an XX male showing Leydig cells in the interstitium and seminiferous tubules containing Sertoli cells. Germ cells are absent.

(above), affected dogs can be screened for those mutations to obtain a definitive diagnosis. As the mechanisms of testis descent are likely conserved in mammals, studies in canine models could be beneficial, increasing our knowledge of the genetic control of testis descent and hastening discovery of the causative mutations for cryptorchidism in humans and domestic animals.

\section{DSD}

\section{Ovotesticular DSD and Testicular DSD}

Several cases of canine XX sex reversal have been reported, with varying degrees of diagnostic certainty [reviewed in Meyers-Wallen and Patterson, 1986], but none has been reported in cats. After confirmation that the trait was inherited in the American Cocker Spaniel (ACS; Selden et al. [1978]), a research colony was subsequently established from that breed. Early studies in this pedigree documented that all affected dogs were $78, \mathrm{XX}$ and had either bilateral testes (testicular DSD, XX male) or ovotestes (ovotesticular DSD, XX true hermaphrodite), and variable external phenotypes [Meyers-Wallen and Patterson, 1988]. Subsequent studies confirmed that affected dogs were $S R Y$-negative, ruling out translocation as the cause [Meyers-Wallen et al., 1999].

Within the ACS research pedigree, approximately $10 \%$ of affected dogs had bilateral testes (XX males). Internally, these dogs had Wolffian duct derivatives and a complete uterus, but no oviducts [Meyers-Wallen and Patter- son, 1988]. Deferent ducts were often identified in the lateral walls of the uterine horns. Externally, XX males were most frequently bilaterally cryptorchid, and had a caudally displaced penis and prepuce with mild hypospadias (fig. 10). The remainder of affected dogs (90\%) usually had bilateral ovotestes, occasionally had an ovary and ovotestis, and rarely a testis paired with an ovotestis (XX true hermaphrodites; Meyers-Wallen and Patterson [1988]). Internally, an epididymis or oviduct, or both, were adjacent to ovotestes. A complete uterus was present. Externally, $15 \%$ had a prepuce-like vulva and 15\% had an enlarged clitoris containing a bone (fig. 11). The remaining $70 \%$ of XX true hermaphrodites had an apparently normal vulva. However, a narrowed caudal vaginal lumen can be present in such dogs. Overall, the degree of phenotypic masculinization was correlated to the proportion of testis in each individual. Biologically active MIS was identified in neonatal testes and ovotestes from affected dogs [Meyers-Wallen et al., 1987]. Notably, the timing of MIS secretion in fetal gonads, as well as the amount of MIS secretion, was delayed [Meyers-Wallen et al., 1994]. This suggests a mechanism for regression of the cranial Müllerian ducts but persistence of the uterus.

Early breeding experiments in the ACS research model indicated the mode of inheritance was compatible with sex-limited autosomal recessive inheritance [MeyersWallen and Patterson, 1988]. Further histologic, cytogenetic and breeding studies in the ACS research pedigree indicated that most affected dogs were sterile. However, estrous cycles have occurred in affected true hermaphro- 

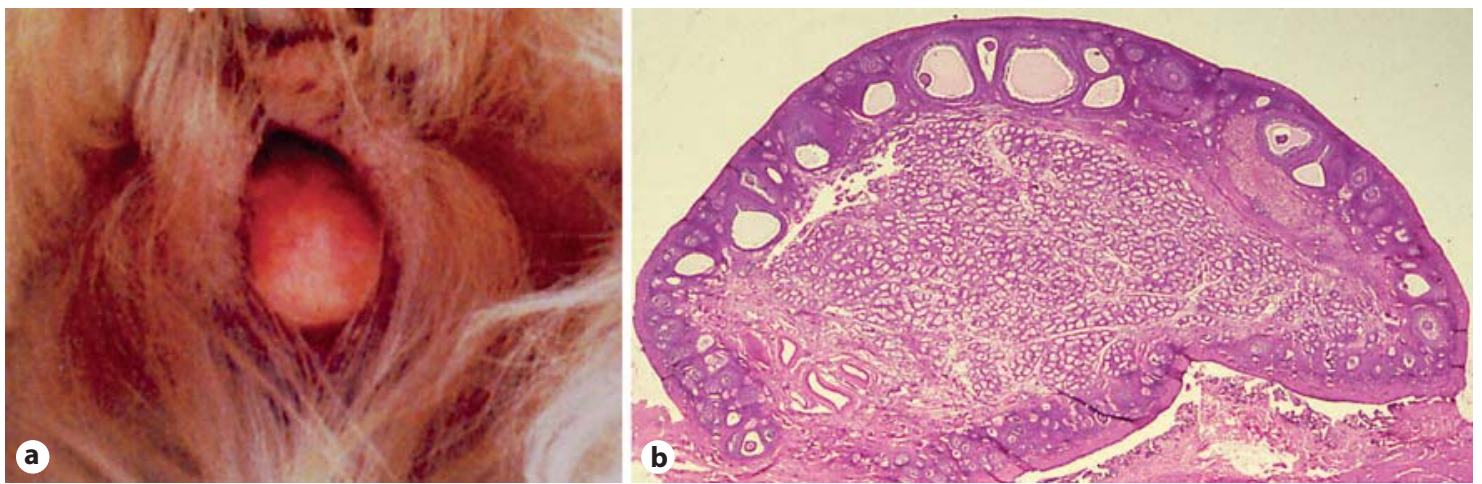

Fig. 11. XX DSD, ovotesticular. ACS with bilateral ovotestes. a A prepuce-like vulva is present and the enlarged clitoris, which contains a bone, protrudes from the vulva. b Ovotestis. The cortex has several stages of ovarian follicles containing oocytes and regressing corpora lutea. The medulla contains Leydig cells in the interstitium and seminiferous tubules containing Sertoli cells only, as in XX males (see fig. 10b) (reprinted with permission from Cold Spring Harbor Laboratory Press: Meyers-Wallen [2006]).

dites, and some of these dogs have produced offspring despite partial masculinization of the external genitalia, including the presence of an enlarged clitoris containing a bone. Male $(78, \mathrm{XY})$ carriers of the trait and obligate heterozygote carrier females have been fertile.

The ACS model is strikingly similar to the subcategory of human XX DSD in which testicular DSD and ovotesticular DSD occur in siblings, or within the same pedigree, and the genetic defect is unknown [Skordis et al., 1987; Ostrer et al., 1989; Palmer et al., 1989; Kuhnle et al., 1993; Ramos et al., 1996; Slaney et al., 1998]. In the ACS model, as in humans, it is likely that the phenotypic variability is related to threshold effects [Sarafoglou and Ostrer, 2000]. In early studies, no candidate genes could be linked to the affected phenotype in dogs from the model pedigree [Kothapalli et al., 2003, 2004, 2005, 2006; Pujar et al., 2005]. Notably, coding mutations in SOX9 are unlikely candidates, as the development of testicular tissue in affected dogs in the absence of SRY and SOX9 function would be unlikely. Although genome wide linkage analysis identified a 5.5-Mb region associated with XX DSD in the model pedigree [Pujar et al., 2007], subsequent fine mapping has not yet identified a causative mutation in that region. Similarly, exon scanning ruled out mutations in the coding region of canine RSPO1, and in affected dogs of most breeds in which XX DSD has been reported [DeLorenzi et al., 2008]. This type of XX DSD has now been reported in at least 28 breeds and 1 mixed breed (table 2). Not all cases that have been cited were tested for SRY, as the test was not available prior to 1995 [MeyersWallen et al., 1995a]. A Robertsonian translocation im- plicating a candidate region on CFA23 was identified in 1 affected dog, but a causative mutation was not identified [Switonski et al., 2011]. While it is possible that this type of XX DSD is genetically heterogeneous in the dog population in general, the mutation is likely to be identical by descent in closely related breeds, such as English and American cocker spaniels.

\section{Androgen Excess \\ Fetal Origin}

Only 1 case of adrenal enzyme deficiency (11-beta hydroxylase deficiency) has been identified in the cat, and none has been reported in the dog. The affected domestic shorthaired cat had normal male external genitalia when examined at 6 months of age except that it appeared to be bilaterally cryptorchid [Knighton, 2004]. A DSD was suspected because the cat had a calico hair coat. As discussed above (XXY, sex chromosome DSD) the feline orange coat color locus is X-linked, therefore males should have either orange or black hair, not both. Normal female internal genitalia were identified and removed during laparotomy. Histology confirmed the presence of Wolffian duct derivatives (epididymides and deferent ducts) as well as ovaries, oviducts and a complete bicornuate uterus. The karyotype was that of a normal female $(38, \mathrm{XX})$. At 10 months of age, the cat was exhibiting polydipsia, polyuria, and male urinary marking behavior. Penile spines were present, which in the cat, are dependent upon sustained androgen stimulation [Aronson and Cooper, 1967]. Resting serum testosterone concentrations were within the normal range for a male cat. High resting serum ACTH concentrations and 
Table 2. Canine breeds in which testicular or ovotesticular XX DSD has been identified

\begin{tabular}{|c|c|}
\hline Species & Reference \\
\hline American Cocker Spaniel & Meyers-Wallen et al., 1995a, 1999 \\
\hline Afghan hound & Meyers-Wallen et al., 1999 \\
\hline American pit bull terrier & Meyers-Wallen et al., 1999 \\
\hline American Staffordshire terrier & Meyers-Wallen, unpublished; Nowacka et al., 2005 \\
\hline Australian shepherd & Meyers-Wallen, unpublished \\
\hline Basset hound & Hubler et al., 1999 \\
\hline Bernese mountain dog & Switonski et al., 2011 \\
\hline Beagle & Williams et al., 1997 \\
\hline Border collie & Meyers-Wallen et al., 1999 \\
\hline Brussels griffon & Meyers-Wallen, unpublished; Poth et al., 2010 \\
\hline Doberman pinscher & Meyers-Wallen et al., 1999 \\
\hline English cocker spaniel & Meyers-Wallen et al., 1999 \\
\hline French bulldog & Meyers-Wallen, unpublished; Campos et al., 2011 \\
\hline German pinscher & Meyers-Wallen, unpublished \\
\hline German shepherd dog & Switonski et al., 2004 \\
\hline German shorthaired pointer & Meyers-Wallen et al., 1995b \\
\hline Golden retriever & Meyers-Wallen, unpublished \\
\hline Jack Russell terrier & Kuiper et al., 2005 \\
\hline Kerry blue terrier & Williamson, 1979 \\
\hline Mixed breed & DeLorenzi et al., 2008 \\
\hline Norwegian elkhound & Melniczek et al., 1999 \\
\hline Podenco dog & Buijtels et al., 2009 \\
\hline Pug $\quad$ - & Stewart et al., 1972; Meyers-Wallen et al., 1999; Rota et al., 2010 \\
\hline Soft coated wheaten terrier & Meyers-Wallen et al., 1999 \\
\hline Tibetan terrier & Meyers-Wallen, unpublished \\
\hline Vizsla & Meyers-Wallen et al., 1999 \\
\hline Walker hound & Meyers-Wallen et al., 1999 \\
\hline Weimaraner & Meyers-Wallen et al., 1999 \\
\hline Wheaten terrier & Meyers-Wallen, unpublished \\
\hline
\end{tabular}

low serum cortisol concentrations after ACTH stimulation suggested adrenal enzyme deficiency. Elevated serum progesterone, 17-hydroxyprogesterone, androstenedione, testosterone, deoxycorticosterone and 11-deoxycorticosterone concentrations indicated that a defect in 11-beta hydroxylase activity was likely. Subsequent to maintenance prednisone therapy, serum testosterone concentrations decreased and clinical signs ceased.

\section{Maternal Origin}

These disorders have not been reported in the cat; however, there are several reports in which canine female fetuses were masculinized by androgens or progesterone preparations administered to the dam during pregnancy. In veterinary practice, androgens have been used to suppress canine estrus. Mibolerone was licensed and marketed for this purpose for several years. In research trials where mibolerone was administered during gestation, the external genitalia of female offspring were masculin- ized [Sokolowski and Kasson, 1978]. Similar results have been observed in clinical practice [Medleau et al., 1983]. Testosterone has been used for estrus suppression in racing greyhounds, often over long periods. When administered during gestation in clinical practice, female offspring developed a prepuce [Olson et al., 1989]. Progestagens induce similar androgen effects in the canine fetus [Curtis and Grant, 1964].

\section{Other}

Müllerian Agenesis/Hypoplasia

In the human syndrome of MURCS (OMIM\#601076), Müllerian duct aplasia/hypoplasia is highly associated with renal agenesis and/or ectopy, and cervicothoracic somite dysplasia, such that if one component is identified, the other anomalies should be investigated. Two case reports suggest that a similar syndrome may occur in cats, although cervicothoracic abnormalities were not reported. The diagnosis in both cats was segmental aplasia of the 
uterine horn with ipsilateral renal agenesis (domestic shorthaired cat, Chang et al. [2008]; Persian cat, Goo et al. [2009]). Furthermore, in a hospital survey of 53,258 cats and 32,660 dogs undergoing elective ovariohysterectomy, congenital uterine abnormalities were identified in $0.09 \%$ of female cats and $0.05 \%$ of female dogs [McIntyre et al., 2010]. These abnormalities included unicornuate uterus, segmental aplasia of 1 uterine horn and uterine horn hypoplasia. In $29.4 \%$ of cats and $50 \%$ of dogs with uterine abnormalities in which the kidneys were also evaluated, ipsilateral renal agenesis was present [McIntyre et al., 2010]. These findings suggest that further careful evaluation of such cases could establish feline and canine models of Müllerian agenesis/hypoplasia or MURCS.

\section{Vaginal Atresia}

Only 1 study of feline vaginal atresia has been reported [Nomura et al., 1997]. The cranial and caudal vagina were separated by connective tissue, suggesting failure of canalization between the Müllerian duct and urogenital sinus. No canine reports were identified.

\section{Summary and Conclusions}

Several types of DSD have been reported in the cat and dog, which are often strikingly similar to those in humans. In addition, cats and dogs share their owners' environments and can act as sentinels for environmental influences on sexual development. Unfortunately, feline and canine models have been infrequently utilized to contribute to our knowledge of mammalian sexual development. Greater awareness on the part of veterinary clini- cians and researchers can lead to better diagnostic tests and establishment of new models for further study. Since genome sequence is now available for both species, and methods to analyze these genomes are rapidly improving, it is possible to pursue the molecular etiology of feline and canine disorders. To efficiently utilize these unique resources as molecular tools continue to improve, it would be helpful to deposit genomic DNA and/or relevant tissue samples from confirmed cases into a repository where they are available to the research community. For example, the Cornell University College of Veterinary Medicine has established a DNA Bank and Biobank for this purpose (Castelhano et al. [2009]; www.vet.cornell.edu/ research/DNABank/). Such a system facilitates collaboration between clinicians and researchers, allowing valuable case material to contribute to our understanding of sexual development long after the case has been reported. This could hasten progress in developing molecular diagnostic tests for humans and animals. The direct benefit to animals is the development of practical tests that can be used to reduce the number of affected cats and dogs produced, particularly in purebred populations.

\section{Acknowledgements}

We thank the many breeders and owners who have donated samples to further research in feline and canine DSD. Animal experimentation in original works by this author cited in this article was conducted in accordance with the guidelines established by the National Institutes of Health and were approved by the Institutional Animal Care and Use Committee at Cornell University. Original work cited in this article was supported in part by the National Institutes of Health (Grant No. HD19393 and HD40351 to V.N.M.-W.).

\section{References}

- Adelsberger ME, Smeak DD: Repair of extensive perineal hypospadias in a Boston terrier using tubularized incised plate urethroplasty. Can Vet J 50:937-942 (2009)

Ader PL, Hobson HP: Hypospadias: a report of three cases. J Am Anim Hosp Assoc 14:721727 (1978).

Aronson LR, Cooper ML: Penile spines of the domestic cat: their endocrine-behavior relations. Anat Rec 157:71-78 (1967).

-Arrighi S, Bosi G, Groppetti D, Aralla M, Cremonesi F: An insight into testis and gubernaculum dynamics of INSL3-RXFP2 signalling during testicular descent in the dog. Reprod Fertil Dev 22:751-760 (2010)
Biggers JD, McFeeley RA: Intersexuality in domestic animals, in McLaren A (ed): Advances in Reproductive Physiology, pp. 30-58 (Logos Press, London 1966).

Bigliardi E, Parma P, Peressotti P, De Lorenzi L, Wohlsein $\mathrm{P}$, et al: Clinical, genetic, and pathological features of male pseudohermaphroditism in dog. Reprod Biol Endocrinol 9:12 (2011).

Bredal WP, Thoresen SI, Kvellestad A, Lindblad $\mathrm{K}$ : Male pseudohermaphroditisim in a cat. J Small Anim Pract 38:21-24 (1997).

Breshears MA, Peters JL: Diagnostic exercise: ambiguous genitalia in a fertile, unilaterally cryptorchid male miniature schnauzer dog. Vet Pathol (2011). 
Cashmore RG, Ladlow JF: Creation of a urethral conduit from a preputial indirect flap in a dog with perineal hypospadias. Vet Surgery 39:14-20 (2010).

-Cassata R, Iannuzzi A, Parma P, DeLorenzi L, Peretti V, et al: Clinical, cytogenetic and molecular evaluation in a dog with bilateral cryptorchidism and hypospadias. Cytogenet Genome Res 120:140-143 (2008).

Castelhano MG, Acland GM, Ciccone PA, Corey EE, Mezey JG, et al: Development and use of DNA archives at veterinary teaching hospitals to investigate the genetic basis of disease in dogs. J Am Vet Med Assoc 234:75-80 (2009).

Centerwall WR, Benirschke K: An animal model for the XXY Klinefelter's syndrome in man: Tortoiseshell and calico male cats. Am J Vet Res 36:1275-1280 (1975).

Chaffaux S, Cribiu EP: Clinical, histological and cytogenetic observations on nine intersex dogs. Gen Sel Evol 23(suppl 1):81-84 (1991).

Chang J, Jung JH, Yoon J, Choi MC, Park JH, et al: Segmental aplasia of the uterine horn with ipsilateral renal agenesis in a cat. J Vet Med Sci 70:641-643 (2008).

Clough E, Pyle RL, Hare WC, Kelly DF, Patterson DF: An XXY sex-chromosome constitution in a dog with testicular hypoplasia and congenital heart disease. Cytogenetics 9:7177 (1970).

Curtis EM, Grant RP: Masculinization of female pups by progestogens. J Am Vet Med Assoc 144:395-398 (1964).

-De Lorenzi L, Groppetti D, Arrighi S, Pujar S, Nicoloso L, et al: Mutations in the RSPO1 coding region are not the main cause of canine SRY-negative XX sex reversal in several breeds. Sex Dev 2:84-95 (2008).

-Gier HT, Marion GB: Development of mammalian testes and genital ducts. Biol Reprod 1: 1-23 (1969).

-Giger U, Meyers-Wallen VN, Patterson DP: A 6-month-old Doberman pinscher with ambiguous genitalia as a first case of X-chromosomal monosomy in the dog. J Vet Intern Med 3:245 (1989).

Goldschmidt B, El-Jaick KB, Souza LM, Carvalho EC, Moura VL, et al: Cryptorchidism associated with 78,XY/79,XXY mosaicism in a dog. Israel J Vet Med 56:56-58 (2001).

Goldschmidt B, Paulino FO, Souza LM, Gomes HF: Infertility related to X-trisomy in a Labrador retriever bitch. J Israeli Vet Med Assoc 58:123-124 (2003).

-Goo MJ, Williams BH, Hong IH, Park JK, Yang $\mathrm{HJ}$, et al: Multiple urogenital abnormalities in a Persian cat. J Feline Med Surg 11:153-155 (2009).

-Grahn RA, Lemesch BM, Millon LV, Matise T, Rogers QR, et al: Localizing the X-linked orange colour phenotype using feline resource families. Anim Genet 36:67-70 (2005).
Hayes HM, Wilson GP: Hospital incidence of hypospadias in dogs in North America. Vet Rec 118:605-607 (1986).

Hayes HM, Wilson GP, Pendergrass TW, Cox VS: Canine cryptorchidism and subsequent testicular neoplasia: case-control study with epidemiologic update. Teratology 32:51-56 (1985).

-Hubler M, Hauser B, Meyers-Wallen VN, Arnold S: Sry-negative XX true hermaphrodite in a Basset Hound. Theriogenology 51:13911403 (1999).

Jakob S, Lovell-Badge R: Sex determination and the control of Sox9 expression in mammals. FEBS J 278:1002-1009 (2011).

Johnston SD, Buoen LC, Madl JE, Weber AF, Smith FO: X-Chromosome monosomy $(37, \mathrm{XO})$ in a Burmese cat with gonadal dysgenesis. J Am Vet Med Assoc 182:986-989 (1983).

Johnston SD, Buoen LC, Weber AF, Madl JE: X trisomy in an Airedale bitch with ovarian dysplasia and primary anestrus. Theriogenology 24:597-607 (1985).

Jurka P, Galanty M, Zielinska P, Max A, Sysa P: Hypospadias in six dogs. Vet Rec 164:331333 (2009).

King GJ, Johnson EH: Hypospadias in a Himalayan cat. J Small Anim Pract 41:508-510 (2000).

Knighton EL: Congenital adrenal hyperplasia secondary to 11beta-hydroxylase deficiency in a domestic cat. J Am Vet Med Assoc 225 238-241 (2004).

Kothapalli K, Kirkness E, Natale L, Meyers-Wallen VN: Exclusion of PISRT1 as a candidate locus for canine Sry-negative XX sex reversal. Anim Genet 34:467-469 (2003).

Kothapalli K, Kirkness E, Pujar S, Van Wormer R, Meyers-Wallen VN: Exclusion of Candidate Genes for Canine SRY-negative XX sex reversal. J Hered 96:759-763 (2005).

-Kothapalli K, Kirkness EF, VanWormer R, Meyers-Wallen VN: Exclusion of DMRT1 as a candidate gene for canine SRY-negative XX sex reversal. Vet J 171:559-561 (2006).

Kothapalli KS, Kirkness EF, Pujar S, MeyersWallen, VN: Exclusion of WT1 as a candidate gene for canine $S R Y$-negative XX sex reversal. Anim Genet 35:466-467 (2004).

Kuhnle U, Schwarz HP, Lohrs U, Stengel-Ruthkowski S, Cleve H, et al: Familial true hermaphroditism: paternal and maternal transmission of true hermaphroditism $(46, \mathrm{XX})$ and XX maleness in the absence of Y-chromosomal sequences. Hum Genet 92:571-576 (1993).

Kuiper H, Hewicker-Trautwein M, Distl O: Cytogenetic and histologic examination of four tortoiseshell cats. Dtsch Tierärztl Wochenschr 110:457-461 (2003).

Kuiper H, Wagner F, Drögemüller C, Distl O Persistent Mullerian duct syndrome causing male pseudohermaphroditism in a mixedbreed dog. Vet Rec 155:400-401 (2004).
Kuiper H, Bunck C, Gunzel-Apel A-R, Drögemüller C, Hewicker-Trautwein M, et al: SRYnegative XX sex reversal in a Jack Russell Terrier: a case report. Vet J 169:116-117 (2005).

Leaman T, Rowland R, Long SE: Male tortoiseshell cats in the United Kingdom. Vet Rec 144:9-12 (1999).

Lofstedt RM, Buoen LC, Weber AF, Johnston SD, Huntington A, et al: Prolonged proestrus in a bitch with $\mathrm{X}$ chromosomal monosomy (77,XO). J Am Vet Med Assoc 200:1104-1106 (1992).

Long SE, Berepubo NA: A 37XO chromosome complement in a kitten. J Small Anim Pract 21:627-631 (1980).

Malouf N, Benirschke K, Hoefnagel D: XX-XY chimerism in a tricolored male cat. Cytogenetics 6:228-241 (1967)

-Marshall LS, Oehlert ML, Haskins ME, Selden JR, Patterson DF: Persistent Mullerian duct syndrome in miniature schnauzers. J Am Vet Med Assoc 181:798-801 (1982).

- Matsuu A, Hashizume T, Kanda T, Nagano M, Sugiyama A, et al: A case of persistent Müllerian duct syndrome with Sertoli cell tumor and hydrometra in a dog. J Vet Med Sci 71: 379-381 (2009)

-Mayenco-Aguirre AM, Padilla JA, Flores JM, Daza MA: Canine gonadal dysgenesis syndrome: a case of mosaicisim $(77, \mathrm{XO} / 78, \mathrm{XX})$. Vet Rec 145:582-584 (1999).

McIntyre RL, Levy JK, Roberts JF, Reep RL: Developmental uterine anomalies in cats and dogs undergoing elective ovariohysterectomy. J Am Vet Med Assoc 237:542-546 (2010).

Medleau L, Johnson CA, Perry RL, Dulisch ML: Female pseudohermaphroditism associated with mibolerone administration in a dog. J Am Anim Hosp Assoc 19:213-215 (1983).

-Melniczek JR, Dambach D, Prociuk U, Jezyk PF, Henthorn PS, et al: Sry-negative XX sex reversal in a family of Norwegian Elkhounds. J Vet Intern Med 13:564-569 (1999).

Meyers-Wallen VN: Inherited abnormalities of sexual development in dogs and cats, in Concannon PW, England G, Verstegen J (eds): Recent Advances in Small Animal Reproduction (International Veterinary Information Service (www.ivis.org) 2001). Document \#A1217.0901

Meyers-Wallen VN: Sex chromosomes, sexual development, and sex reversal in the dog, in Ostrander EA, Giger U, Lindblad-Toh K (eds): The Dog and Its Genome, pp. 383-405 (Cold Spring Harbor Laboratory Press, Cold Spring Harbor, NY 2006).

Meyers-Wallen VN: Review and Update: Genomic and Molecular Advances in Sex Determination and Differentiation in Small Animals. Reprod Domest Anim 44 Suppl 2: 40-46 (2009)

Meyers-Wallen VN, Patterson DF: Disorders of sexual development, in Morrow DA (ed): Current Therapy in Theriogenology, pp. 567574 (WB Saunders Co., Philadelphia 1986). 
Meyers-Wallen VN, Patterson DF: XX sex reversal in the American cocker spaniel dog: phenotypic expression and inheritance. Hum Genet 80:23-30 (1988).

Meyers-Wallen VN, Patterson DF: Disorders of sexual development in the dog, in Kirk RW, Bonagura JD (eds): Current Veterinary Therapy: Small Animal Practice, 10th ed., pp. 1261-1269 (WB Saunders, Philadelphia 1989).

- Meyers-Wallen VN, Donahoe PK, Manganaro T, Patterson D: Mullerian inhibiting substance in sex-reversed dogs. Biol Reprod 37:10151022 (1987).

Meyers-Wallen VN, Wilson JD, Griffin JE, Fisher S, Moorhead PH, et al: Testicular feminization in a cat. J Am Vet Med Assoc 195:631634 (1989a).

Meyers-Wallen VN, Donahoe PK, Ueno S, Manganaro T, Patterson DF: Mullerian inhibiting substance is present in testes of dogs with persistent Mullerian duct syndrome. Biol Reprod 41:881-888 (1989b).

-Meyers-Wallen VN, Lee MM, Manganaro TF, Kuroda T, McLaughlin D, et al: Mullerian inhibiting substance is present in embryonic testes of dogs with persistent Mullerian duct syndrome. Biol Reprod 48:1410-1418 (1993).

- Meyers-Wallen VN, MacLaughlin D, Palmer V, Donahoe PK: Mullerian inhibiting substance secretion is delayed in XX sex reversed dog embryos. Mol Reprod Dev 39:1-7 (1994).

- Meyers-Wallen VN, Palmer VL, Acland GM, Hershfield B: Sry-negative XX sex reversal in the American cocker spaniel dog. Mol Reprod Dev 41:300-305 (1995a).

-Meyers-Wallen VN, Bowman L, Acland GM, Palmer VL, Schlafer D, et al: Sry-negative XX sex reversal in the German shorthaired pointer dog. J Hered 86:369-374 (1995b).

-Meyers-Wallen VN, Schlafer D, Barr I, LovellBadge R, Keyzner A: Sry-negative XX sex reversal in purebred dogs. Mol Reprod Dev 53: 266-273 (1999).

-Millis DL, Hauptmann JG, Johnson CA: Cryptorchidism and monorchidism in cats: 25 cases (1980-1989). J Am Vet Med Assoc 200: 1128-1130 (1992).

-Moran C, Gillies CB, Nicholas F: Fertile male tortoiseshell cats. Mosaicisim due to gene instability? J Hered 75:397-402 (1984).

Ndikuwera J: A case of hypospadias in a dog. Ir Vet J 58:504-506 (2005).

-Nickel RF, Ubbink G, van der Gaag I, van Sluijs FJ: Persistent Mullerian duct syndrome in the basset hound. Tijdschr Diergeneeskd 117 Suppl 1:31S (1992).

- Nie GJ, Johnston SD, Hayden DW, Buoen LC, Stephens M: Theriogenology question of the month. Azoospermia associated with $79, \mathrm{XXY}$ chromosome complement (canine Klinefelter's syndrome). J Am Vet Med Assoc 212:1545-1547 (1998).
Nomura K, Koreeda T, Kawata M, Shiraishi Y: Vaginal atresia with transverse septum in a cat. J Vet Med Sci 59:1045-1048 (1997)

Norby DE, Hegreberg GA, Thuline HC, Findley D: An XO cat. Cytogen Cell Genet 13:448453 (1974).

Nowacka J, Nizanski W, Klimowicz M, Dzimira S, Switonski M: Lack of the SOX9 gene polymorphism in sex reversal dogs (78,XX; SRY negative). J Hered 96:797-802 (2005).

O'Connor CL, Schweizer C, Gradil C, Schlafer D, Lopate C, et al: Case Report: Trisomy-X with estrus cycle anomalies in the bitch. Theriogenology 76:374-380 (2011).

Olson PN, Seim HB, Park RD, Grandy JL, Freshman JL, et al: Female pseudohermaphroditism in three sibling greyhounds. J Am Vet Med Assoc 194:1747-1749 (1989).

Ostrer H, Wright G, Clayton M, Skordis N, MacGillivray $\mathrm{MH}$ : Familial XX chromosomal maleness does not arise from a Y chromosomal translocation. J Pediatr 114:977-982 (1989).

- Palmer MS, Sinclair AH, Berta P, Ellis NA, Goodfellow PN, et al: Genetic evidence that $\mathrm{ZFY}$ is not the testis-determining factor. Nature 342:937-939 (1989).

Pasterski V, Prentice P, Hughes IA: Impact of the consensus statement and the new DSD classification system. Best Practice Res Clin Endocrinol Metab 24:187-195 (2010).

Peter AT, Markwelder D, Asem EK: Phenotypic feminization in a genetic male dog caused by nonfunctional androgen receptors. Theriogenology 40:1093-1105 (1993).

Poth T, Breuer W, Walter B, Hecht W, Hermanns W: Disorders of sex development in the dog - adoption of a new nomenclature and reclassification of reported cases. Anim Reprod Sci 121:197-207 (2010).

- Pujar S, Meyers-Wallen VN: A molecular diagnostic test for persistent Müllerian duct syndrome in miniature schnauzer dogs. Sex Dev 3:326-328 (2009).

- Pujar S, Kothapalli KS, Kirkness EF, VanWormer RH, Meyers-Wallen VN: Exclusion of Lhx 9 as a candidate gene for Sry-negative XX sex reversal in the American cocker spaniel model. J Hered 96:452-454 (2005).

-Pujar S, Kothapalli KSD, Göring HH, MeyersWallen VN: Linkage to CFA29 detected in a genome wide linkage screen of a canine pedigree segregating Sry-negative XX sex reversal. J Hered 98:438-444 (2007).

-Ramos ES, Moreira-Filho CA, Vicente YA, Llorach-Velludo MA, Tucci S, et al: SRY-negative true hermaphrodites and an XX male in two generations of the same family. Hum Genet 97:596-598 (1996).

Reif JS, Maguire TG, Kenney RM, Brodey RS: A cohort study of canine testicular neoplasia. J Am Vet Med Assoc 175:719-723 (1979).

- Reimann-Berg N, Escobar HM, Nolte I, Bullerdiek J: Testicular tumor in an XXY dog. Cancer Genet Cytogenet 183:114-116 (2008).
Rota A, Cucuzza AS, Iussich S, De Lorenzi L, Parma P: The case of an SRY-negative XX male Pug with an inguinal gonad. Reprod Domest Anim 45:743-745 (2010).

Sarafoglou K, Ostrer H: Familial sex reversal: A review. J Clin Endocrin Metabol 85:483-493 (2000).

Schlafer DH, Valentine B, Fahnestock G, Froenicke L, Grahn RA, et al: A case of SRY-positive 38, XY true hermaphroditism (XY sex reversal) in a cat. Vet Pathol 48:822-827 (2011).

Schulman J, Levine SH: Pyometra involving uterus masculinus in a cat. J Am Vet Med Assoc 194:690-691 (1989).

Delden JR, Wachtel SS, Koo GC, Haskins ME, Patterson DF: Genetic basis of XX male syndrome and XX true hermaphroditism: evidence in the dog. Science 201:644-646 (1978).

Skordis NA, Stetka DG, MacGillivray $\mathrm{MH}$, Greenfield S: Familial 46,XX males coexisting with familial 46, XX true hermaphrodites in same pedigrees. J Pediatr 110:244248 (1987).

-Slaney SF, Chalmers IJ, Affara NA, Chitty LS: An autosomal or $\mathrm{X}$ linked mutation results in true hermaphrodites and 46,XX males in the same family. J Med Genet 35:17-22 (1998).

Smith FW Jr, Buoen LC, Weber AF, Johnston SD, Randolph JF, et al: X-chromosomal monosomy $(77, \mathrm{XO})$ in a Doberman Pinscher with gonadal dysgenesis. J Vet Intern Med 3:9095 (1989).

Sokolowski JH, Kasson CW: Effects of mibolerone on conception, pregnancy, parturition, and offspring in the Beagle. 1978. Am J Vet Res 39:837-839 (1978).

- Stewart RW, Menges RW, Selby LA, Rhoades JD, Crenshaw DB: Canine intersexuality in a pug breeding kennel. Cornell Vet 62:464-473 (1972).

Switonski M, Godynicki S, Jackowiak H, Pienkowska A, Turczuk-Bierla I, et al: X trisomy in an infertile bitch: cytogenetic, anatomic, and histologic studies. J Hered 91:149-150 (2000).

Switonski M, Szczerbal I, Grewling J, Antosik P, Nizanski W, et al: Two cases of infertile bitches with 78,XX/77,X mosaic karyotype: a need for cytogenetic evaluation of dogs with reproductive disorders. J Hered 94:65-68 (2003).

Switonski M, Nowacka J, Skorczyk A, Chmurzynska A, Nizanski W: Hereditary sex-reversal syndrome (78,XX; SRY-negative) in German Shepherd puppies. Medycyna weterynaryjna 60:705-707 (2004).

Switonski M, Szczerbal I, Nizanski W, Kociucka B, Bartz M, et al: Robertsonian translocation in a sex reversal dog (XX, SRY negative) may indicate that the causative mutation for this intersexuality syndrome resides on canine chromosome 23 (CFA 23). Sex Dev 5:141-146 (2011). 
Thomsen PD, Byskov AG, Basse A: Fertility in two cats with X-chromosome mosaicism and unilateral ovarian dysgenesis. J Reprod Fert 80:43-47 (1987).

Tomboc M, Lee PA, Mitwally MF, Schneck FX, Bellinger $M$, et al: Insulin-like 3/relaxin-like factor gene mutations are associated with cryptorchidism. J Clin Endocrinol Metab 85: 4013-4018 (2000).

-Vegter AR, Kooistra HS, van Sluijs FJ, van Bruggen LW, Ijzer J, et al: Persistent Mullerian duct syndrome in a Miniature Schnauzer dog with signs of feminization and a Sertoli cell tumour. Reprod Domest Anim 45:447452 (2010).
Villagomez DA, Parma P, Radi O, Di Meo G, Pinton A, et al: Classical and molecular cytogenetics of disorders of sexual development in domestic animals. Cytogenet Genome Res 126:110-131 (2009).

Wernham BG, Jerram RM: Male pseudohermaphroditism in a Labrador Retriever, and a review of mammalian sexual differentiation. NZ Vet J 54:248-252 (2006).

Williams J, Partington BP, Smith B, Hedlund CS, Law JM: Pyovagina and stump pyometra in a neutered XX sex-reversed beagle: a case report. J Am Anim Hosp Assoc 33:83-90 (1997).

Williamson JH: Intersexuality in a family of Kerry blue terriers. J Hered 70:138-139 (1979).
Wu X, Wan S, Pujar S, Haskins ME, Schlafer DH, et al: A single base pair mutation encoding a premature stop codon in the MIS type II receptor is responsible for canine persistent Müllerian duct syndrome. J Androl 30:4656 (2009)

Yates D, Hayes G, Heffernan M, Beynon R: Incidence of cryptorchidism in dogs and cats. Vet Rec 152:502-504 (2003).

Zhao X, Du ZQ, Rothschild MF: An association study of 20 candidate genes with cryptorchidism in Siberian Husky dogs. J Anim Breed Genet 127:327-331 (2010). 